\title{
EFFICACY OF SCREEN RECORDING IN THE OTHER-REVISION OF TRANSLATIONS: EPISODIC MEMORY AND EVENT MODELS
}

\author{
Gregory M. Shreve \\ Kent State University (USA) \\ gshreve@kent.edu \\ Erik Angelone \\ Kent State University (USA) \\ eangelon@kent.edu \\ Isabel Lacruz \\ ilacruz@kent.edu \\ Kent State University (USA)
}

\begin{abstract}
In a 2011 study, Angelone compared the self-revision results of graduate German translation students. Participants documented their original translations using Integrated Problem and Decision Reporting (IPDR) logs (Gile 2004), think-aloud protocols and screen recordings. They then used this documentation to assist self-revision of their translations. Angelone found a significant improvement in error detection overall and in each of six discrete error categories when participants used screen recordings to assist their self-revision. We sought to partially replicate Angelone's findings concerning the efficacy of screen recording in translation revision. Instead of focusing on self-revision, we studied other-revision and broadened our scope to examine the behavior of graduate students in both Spanish and German translation. We hypothesized that error analysis overall would show that screen recording would again prove to be a more efficacious process protocol in support of revision than IPDR logs, as was the case in Angelone's study. We also hypothesized that we would replicate his findings for each of the six error categories. The results partially confirmed Angelone's results: screen recordings were significantly more efficacious than IPDR logs in overall error mitigation.
\end{abstract}




\section{Resumen}

En un estudio de 2011, Angelone comparó los resultados de auto-revisión de estudiantes graduados de traducción alemán-inglés. Los participantes documentaron sus traducciones originales mediante registros integrados de problemas y decisiones (IPDR, por sus siglas en inglés; Gile 2004), protocolos de pensamiento en voz alta, y grabaciones de pantalla. Después utilizaron esta documentación para facilitar la autorevisión de sus traducciones. Angelone encontró una mejora significativa general en la detección de errores y, en particular, en seis categorías específicas de errores cuando los participantes utilizaron las grabaciones de pantalla para sustentar su auto-revisión. En este estudio intentamos replicar parcialmente los resultados de Angelone con respecto a la eficacia de las grabaciones de pantalla para revisar traducciones. En lugar de centrarnos en la auto-revisión, estudiamos la revisión de traducciones ajenas. Según nuestra hipótesis de partida, el análisis de errores en general mostraría que las grabaciones de pantalla resultarían ser de nuevo un protocolo de proceso más eficaz en apoyo de la revisión que los registros IPDR, como en el estudio de Angelone. Otra hipótesis consistía en que replicaríamos sus resultados en cada una de las seis categorías de errores. Los resultados confirmaron parcialmente los obtenidos por Angelone: las grabaciones de pantalla fueron significativamente más eficaces que los registros IPDR en la mitigación general de errores.

Keywords: Translation revision. Integrated Problem and Decision Reporting. Screen recording. Episodic memory. Event segmentation theory.

Palabras clave: Revisión en traducción. Registros integrados de problemas y decisiones. Grabación de pantalla. Memoria episódica. Teoría de la segmentación de eventos.

Manuscript received on March 28, 2013 and accepted on September 25, 2013. 


\section{Introduction: Efficacy of screen recording in self-revision}

Revision processes in translation are, according to Künzli (2007: 115), a "distinct and hitherto often neglected component of the overall process of producing translations." Increasingly, scholars are turning their attention to the nature of translation revision, focusing on where and how it occurs and the role it plays in the overall translation process. For instance, a recent study by Massey, Ehrensberger-Dow \& Hunziker Heeb (2013) seems to show significant differences in revision behavior between professionals and students and questions some assumptions about where revision primarily occurs, in the drafting phase or the post-drafting phase. The authors' results suggest that "revisions are actually a more prominent feature of what has been termed the drafting phase than of the post-drafting phase." Carl, Dragsted \& Jakobsen (2010: 8) similarly found a "clear preference among the translators for allocating more time to the drafting phase than to the end revision phase." While it is not our intent here to review the literature on revision, it is clear that the discipline has increasingly turned its attention to translation revision processes.

There are pedagogical implications to translation revision research. Clearly, if revision processes play a critical role in producing accurate and acceptable target texts, then we should expose students to revision as a discrete topic during their training, the same way we expose them to translation strategies, for instance. As Erik Angelone (2013: 1) argues, recent advances in translation research technology and method (eye tracking, keystroke logging, screen recording) can be harnessed to foster the student translator's "cognizance of how one translates," including helping them understand the nature of revision. Modern translation pedagogy is increasingly "process aware;" this means that pedagogical methods, activities and objectives should reflect clear, empirically-based understandings of the cognitive bases of translation. Kiraly (1995: 11) was one of the first advocates of a translation curriculum "based on a theoretically adequate description of translation behavior."

Thus, research studies such as the one described here and Angelone's 2011 study, aim directly at serving process-oriented translation pedagogy. 
The studies use process research to explicate self- and other-revision but, in the form of learning activities, they also foster reflection and self-awareness in students of the problems they encounter and the quality of the solutions they generate. Revision research is quite useful pedagogically because it sheds light on issues central to the development of expertise: improved problem recognition and resolution, error recognition and correction processes, and monitoring / control processes (see Shreve 2006).

In his 2011 study, Angelone compared the self-revision results of graduate German translation students employing three different translation "process protocols," defined here as student-generated documentation of readily observable problems and problem-solving behaviors. In conjunction with a total of nine translation tasks, participants created one of the following three protocol types: (1) an Integrated Problem and Decision Report log (IPDR; see Gile 2004); (2) a think-aloud protocol (TAP); or (3) a screen recording (SR). Three protocols were created for each type. Students were given the opportunity to utilize these process protocols as a point of departure in making any desired revisions before submitting their translations for error encoding. In other words, the protocols were utilized as revision tools for recognizing and addressing problems. Angelone evaluated the resulting translations for errors in six categories (punctuation, spelling, lexis, syntax, style, mistranslation) and tabulated the overall number of errors in the translation as well as the number of errors in each error category in relation to process protocol type used for purposes of revision.

Angelone (2013: 267) found a significant improvement in error mitigation during the revision phase when participants used screen recording to assist self-revision. By error mitigation we mean that participants, through application of the respective process protocol, recognized and corrected errors they had overlooked during initial translation task completion. Screen recording proved to be the most effective support for mitigation across all error categories, from smaller, more granular errors (punctuation, spelling) to larger, more textual ones (style).

Angelone's finding about the efficacy of screen recording raised some interesting questions. First, would screen recording also be more efficacious if it were employed to assist other-revision? Second, if that were to be the case, what is a possible cognitive explanation for these results: how and why does screen recording improve error mitigation in both other- and self-revision? 


\section{Efficacy of screen recording in other-revision: Study and method}

To answer the first question, we conducted a small study in October 2012 to see if we could (at least partially) replicate Angelone's results. In our study, graduate Spanish and German translation students translated a set of two experimental texts under two process protocol conditions: IPDR documentation, and SR documentation. In other words, they created an IPDR log in conjunction with one translation task and a screen recording in conjunction with the other. Think-aloud protocols were not used in this study. The decision to compare only two protocol types was reached in order to simplify the study and can be justified by the fact that the TAP and IPDR results in Angelone's original study were similar insofar as error frequency ranges were concerned. While there were some differences, both methods performed at about the same level relative to SR recordings. ${ }^{1}$ Thus, if, in our study, SR outperformed IPDR, then it would also most likely have outperformed TAP.

Our study transpired over the course of two sessions. After an initial translation session, participants took part in a second session where they revised the translations of fellow translators using the IPDR and SR protocol documentation captured during the original translation. Our first hypothesis was that screen recording would be more efficacious in support of other-revision than IPDR documentation, in line with the result in Angelone's study of self-revision. Our second hypothesis was that screen recording would be more efficacious in support of revision than IPDR documentation in each error category, as was the result in Angelone's preceding study.

\subsection{Participants}

A total of twelve participants took part in the study. Six were students in the Spanish track of our Master's program, four were students in the German track of the program, and two were recent graduates of the Spanish track with less than three years of professional translation experience. Among the eight participants in or from the Spanish track, four were English L1. Among the four participants in the German track, two were English L1.

Of the twelve participants, five had received formal training in editing their own translations, and six had received formal training in the editing of translations produced by others. Four of the participants had professional

1. For example, when using TAPs as a framework protocol for revisions, mistranslation errors tended to go unnoticed more frequently than when IPDR logs were used, but this frequency of occurrence differentiation was minimal, particularly in relation to the significantly lower frequencies when screen recordings were used. 
experience in editing. Although six of the participants in this study had some level of professional translation and/or editing experience, we primarily wanted to explore the relative efficacy of the respective diagnostic tools when used by students of translation and therefore did not look for an expertise effect in the study.

None of the participants had prior experience in other-revision of translations using IPDR logs or screen recordings as process protocols. Both approaches were briefly explained and modeled for the participants at the outset of the follow-up revision task.

\subsection{Materials and procedures}

Data were collected over the course of two related sessions. Four texts were selected in German and four in Spanish from short travel brochures (approx. 80 words each). During the first session, all twelve participants translated two of the texts from either Spanish or German into English. They were instructed that the translations should target English-speaking tourists visiting the various destinations depicted in the brochures, and that the purpose of the translations would be to present the destinations in an attractive light. The tasks were carried out on a laptop computer, and students had access to online resources during task completion. Although the translation tasks were not timed, participants spent approximately forty-five minutes on each of their two translations.

During the first of the two translations, participants were asked to create an IPDR log, documenting the following information in a columned format: (1) problems, as encountered in the ST; (2) a brief description of the nature of the problems; (3) a brief discussion of the decision-making and strategies utilized in addressing the problems; and (4) solutions, as they appeared in the TT. As in Angelone's study, participants needed to temporarily break away from the task at hand to enter this content since log documentation and translation proceeded concurrently. Minimum or maximum IPDR entries were not stipulated, and participants created the log using an MS Word document template provided by the researchers.

For the second of the two translations, a screen recording documenting all on-screen activity that took place during task completion was captured using the Blueberry Flashback Express software application. The default "full screen" setting was used for recording purposes. No audio data were collected. Participants were informed that the application would be running in the background as they worked. Researchers started recording at the onset of the translation task and stopped recording upon task completion. Other than 
that, researchers were not present while participants completed the tasks. After the students finished the translations, all files (two translations, one $\log$, and one screen recording for each participant) were saved.

The second phase of this study took place one week after the first (translation) session ended. During the second session, participants were asked to revise two translations created by another participant in the study. As was the case with the translations, the two revision sessions were not timed. However, participants spent approximately thirty minutes in each session. Revisions were made directly in the MS Word files containing the translations. Participants were instructed to use the process protocol created during the translation (either a log or a screen recording) as a tool for recognizing and fixing any errors in the translation. They were instructed to correct any errors they found in the translation, including any that were not explicitly documented or indicated in the accompanying process protocol. Before revision commenced, the researchers gave the participants an idea of what to look for in the screen recordings as potential indicators of problems that might warrant double-checking in the corresponding translations (extended pauses in screen activity, look-ups/information retrieval, and concurrent revision activity).

The texts to be translated and revised as well as the documentation method used (SR vs. IPDR log) were counterbalanced across subjects according to the rotation specified in table 1. This rotation was used once for the four German participants and twice for the eight Spanish participants.

\begin{tabular}{|l|l|l|l|l|}
\hline \multirow{2}{*}{} & \multicolumn{2}{|c|}{ Session I - Translate } & \multicolumn{2}{c|}{ Session II - Revise } \\
\cline { 2 - 5 } & \multicolumn{1}{|c}{ Task $\mathbf{1}$} & \multicolumn{1}{|c|}{ Task 2} & Task $\mathbf{1}$ & Task $\mathbf{2}$ \\
\hline Participant 1 & Text A - SR & Text B - IPDR & Text C - IDPR & Text D - SR \\
\hline Participant 2 & Text C - IPDR & Text D - SR & Text A - SR & Text B - IPDR \\
\hline Participant 3 & Text C - SR & Text A - IPDR & Text D - IDPR & Text B - SR \\
\hline Participant 4 & Text D - IPDR & Text B - SR & Text C - SR & Text A - IPDR \\
\hline
\end{tabular}

Table 1. Rotation of texts and documentation methods.

During the revision sessions using the process protocols, participants were not bound to take a set approach. In other words, they were informed that they could first review the process protocol in its entirety and then go to the translation and make revisions; they could analyze the process protocol and make revisions synchronously; or they could make revisions and then review the process protocol for verification purposes afterwards. 


\begin{tabular}{|c|c|c|c|c|c|c|c|c|c|c|c|c|c|c|c|}
\hline \multirow{2}{*}{$\begin{array}{c}\text { Part. } \\
\text { Text }\end{array}$} & \multicolumn{2}{|c|}{ Errors } & \multirow{2}{*}{$\begin{array}{c}\% \% \\
\text { Fixed }\end{array}$} & \multicolumn{2}{|c|}{ PU error } & \multicolumn{2}{|c|}{ SP error } & \multicolumn{2}{|c|}{ LEX error } & \multicolumn{2}{|c|}{ SYN error } & \multicolumn{2}{|c|}{ STY error } & \multicolumn{2}{|c|}{ MIS error } \\
\hline & TT & RTT & & TT & RTT & TT & RTT & TT & RTT & TT & RTT & TT & RTT & TT & RTT \\
\hline \multicolumn{16}{|c|}{ DE-IPDR } \\
\hline 1 (B) & 10 & 6 & 40.0 & 1 & 1 & 1 & 1 & 2 & 1 & 0 & 0 & 1 & 1 & 5 & 2 \\
\hline $2(C)$ & 10 & 7 & 30.0 & 1 & 1 & 0 & 0 & 1 & 0 & 0 & 0 & 1 & 0 & 7 & 6 \\
\hline $3(\mathrm{~A})$ & 2 & 1 & 50.0 & 0 & 0 & 0 & 0 & 2 & 1 & 0 & 0 & 0 & 0 & 0 & 0 \\
\hline $4(\mathrm{D})$ & 3 & 3 & 00.0 & 0 & 0 & 0 & 0 & 0 & 0 & 0 & 0 & 0 & 0 & 3 & 3 \\
\hline \multicolumn{16}{|c|}{ DE-SR } \\
\hline $1(\mathrm{~A})$ & 6 & 1 & 83.3 & 3 & 1 & 0 & 0 & 1 & 0 & 0 & 0 & 1 & 0 & 1 & 0 \\
\hline $2(\mathrm{D})$ & 10 & 2 & 80.0 & 1 & 0 & 0 & 0 & 1 & 0 & 1 & 0 & 1 & 1 & 6 & 1 \\
\hline $3(\mathrm{C})$ & 5 & 4 & 20.0 & 1 & 1 & 0 & 0 & 0 & 0 & 1 & 0 & 1 & 1 & 2 & 2 \\
\hline $4(B)$ & 10 & 3 & 70.0 & 2 & 0 & 0 & 0 & 0 & 0 & 1 & 0 & 2 & 1 & 5 & 2 \\
\hline \multicolumn{16}{|c|}{ ES-IPDR } \\
\hline $1(\mathrm{~B})$ & 4 & 4 & 00.0 & 0 & 0 & 0 & 0 & 1 & 1 & 0 & 0 & 1 & 1 & 2 & 2 \\
\hline $2(C)$ & 12 & 8 & 33.3 & 0 & 0 & 0 & 0 & 6 & 3 & 0 & 0 & 0 & 0 & 6 & 5 \\
\hline $3(\mathrm{~A})$ & 10 & 8 & 20.0 & 1 & 1 & 1 & 0 & 2 & 2 & 0 & 0 & 1 & 1 & 5 & 4 \\
\hline $4(\mathrm{D})$ & 8 & 5 & 37.5 & 0 & 0 & 1 & 0 & 2 & 1 & 0 & 0 & 2 & 1 & 3 & 3 \\
\hline 5 (B) & 15 & 8 & 46.7 & 1 & 0 & 0 & 0 & 4 & 3 & 2 & 0 & 3 & 2 & 5 & 3 \\
\hline $6(\mathrm{C})$ & 12 & 7 & 41.7 & 0 & 0 & 0 & 0 & 3 & 2 & 1 & 0 & 0 & 0 & 8 & 5 \\
\hline 7 (A) & 9 & 7 & 22.2 & 0 & 0 & 0 & 0 & 3 & 3 & 1 & 1 & 3 & 1 & 2 & 2 \\
\hline $8(\mathrm{D})$ & 12 & 8 & 33.3 & 1 & 0 & 0 & 0 & 1 & 1 & 0 & 0 & 3 & 1 & 7 & 6 \\
\hline \multicolumn{16}{|l|}{ ES-SR } \\
\hline $1(\mathrm{~A})$ & 11 & 7 & 36.4 & 1 & 1 & 0 & 0 & 2 & 2 & 0 & 0 & 1 & 1 & 7 & 3 \\
\hline $2(\mathrm{D})$ & 11 & 4 & 63.6 & 0 & 0 & 0 & 0 & 1 & 1 & 0 & 0 & 3 & 0 & 7 & 3 \\
\hline $3(\mathrm{C})$ & 8 & 5 & 37.5 & 1 & 0 & 0 & 0 & 5 & 5 & 0 & 0 & 0 & 0 & 2 & 0 \\
\hline $4(B)$ & 8 & 5 & 37.5 & 0 & 0 & 0 & 0 & 1 & 0 & 1 & 1 & 2 & 2 & 4 & 2 \\
\hline $5(\mathrm{~A})$ & 13 & 5 & 61.5 & 1 & 1 & 1 & 0 & 3 & 0 & 3 & 0 & 2 & 1 & 3 & 3 \\
\hline $6(\mathrm{D})$ & 8 & 5 & 37.5 & 0 & 0 & 0 & 0 & 3 & 1 & 1 & 1 & 1 & 1 & 3 & 2 \\
\hline 7 (C) & 12 & 9 & 25.0 & 2 & 1 & 0 & 0 & 7 & 7 & 2 & 0 & 0 & 0 & 1 & 1 \\
\hline 8 (B) & 10 & 5 & 50.0 & 0 & 0 & 0 & 0 & 1 & 1 & 1 & 0 & 1 & 0 & 6 & 4 \\
\hline
\end{tabular}

Table 2. Efficacy of IPDR logs and screen recordings in error mitigation (PU=Punctuation $\mathrm{SP}=$ Spell LEX=Lexical Error SYN = Syntax STY= Style MIS=Mistranslation).

Once the second phase was complete, all translations (TT) and their revised versions (RTT) were evaluated for errors. We used the same error categories employed in Angelone's original study: punctuation, spelling, lexis, syntax, style, and mistranslation. Overall error frequencies and error frequencies by type were calculated for the translated texts before other-revision and after other-revision. Lexis errors included such things as using the wrong term or word, collocation errors, and word form errors. Syntax errors included word order errors or errors in subject/verb agreement. Stylistic errors involved, for 
example, problems in register and problems at the level of genre conventions. Finally, mistranslation errors comprised erroneous additions or omissions as well as apparent miscomprehension errors.

\section{Results}

The percentage of errors mitigated in the revised texts was calculated. Overall, the mean percentage of errors mitigated was $50.4 \%$ when the reviser had access to the translators' screen recordings and $29.6 \%$ when the reviser had access to the translators' logs. The raw data for each participant in each of the languages for each process protocol mode is given in table 2 .

A $2 \times 2$ mixed analysis of variance (ANOVA) was performed with process protocol as a within-subjects independent variable with two levels (screen recording and IPDR log), and language as a between-subjects independent variable with two levels (German and Spanish). For the means, see table 3 and figure 1 .

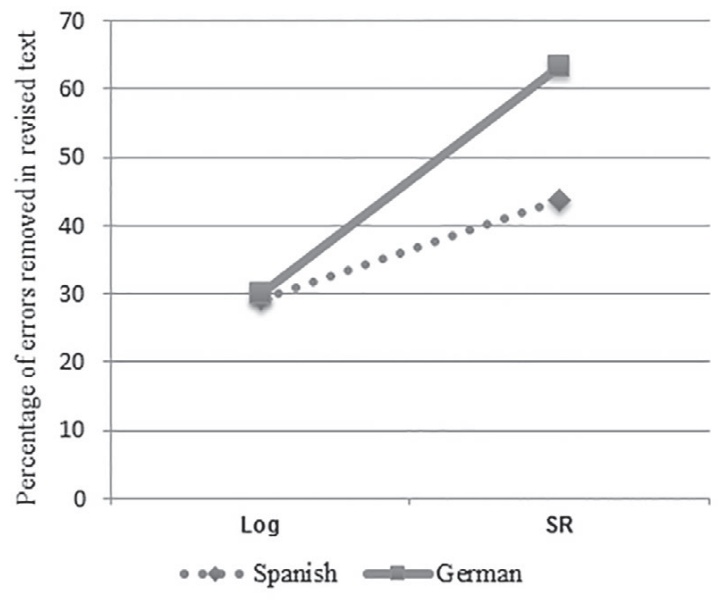

Figure 1. Analysis of variance results.

\begin{tabular}{|l|c|c|c|}
\hline & Screen recording & IPDR log & Process protocol effect \\
\hline Spanish & 43.6 & 29.3 & $+14.3^{*}$ \\
\hline German & 63.3 & 30.0 & $+33.3^{*}$ \\
\hline Combined & 50.4 & 29.6 & $+20.8^{*}$ \\
\hline
\end{tabular}

Table 3. Mean percentage of errors removed in the revised texts (statistically significant differences indicated by ${ }^{*}$ ). 
The main effect of process protocol was significant, $\mathrm{F}(1,10)=8.506$, $\mathrm{p}<$ .05. Thus, the overall (German and Spanish together) percentage of errors remaining in the revised texts was significantly lower when the revisers had access to the translators' screen recordings than when they had access to the translators' IPDR logs.

The overall mean percentage of errors removed was 36.6\% for the Spanish edited texts and $46.7 \%$ for the German revised texts. The main effect of language was not significant, $\mathrm{p}>0.05$. Thus, the overall (screen recording and IPDR log together) percentage of errors removed in the revised Spanish texts was not significantly different from the overall percentage of errors removed in the revised German texts. The interaction between process protocol and language was not significant, $\mathrm{p}>0.05$. This means that the main effect of process protocol was significant for both languages.

An analysis of the number of errors mitigated by the two process protocols shows that, overall, SR was most effective in reducing the frequency of errors. Out of a total of 107 TT errors, IPDR-supported revision only mitigated 35 errors, leaving 72 (32.7\% mitigation). Screen recording, on the other hand, mitigated 56 out of 111 TT errors, leaving 55 (50.4\% mitigation). Figure 2 graphically illustrates the overall efficacy of both process protocols. These findings confirm our first hypothesis, namely that SR would be more efficacious than IPDR protocols in overall error mitigation in other-revision.

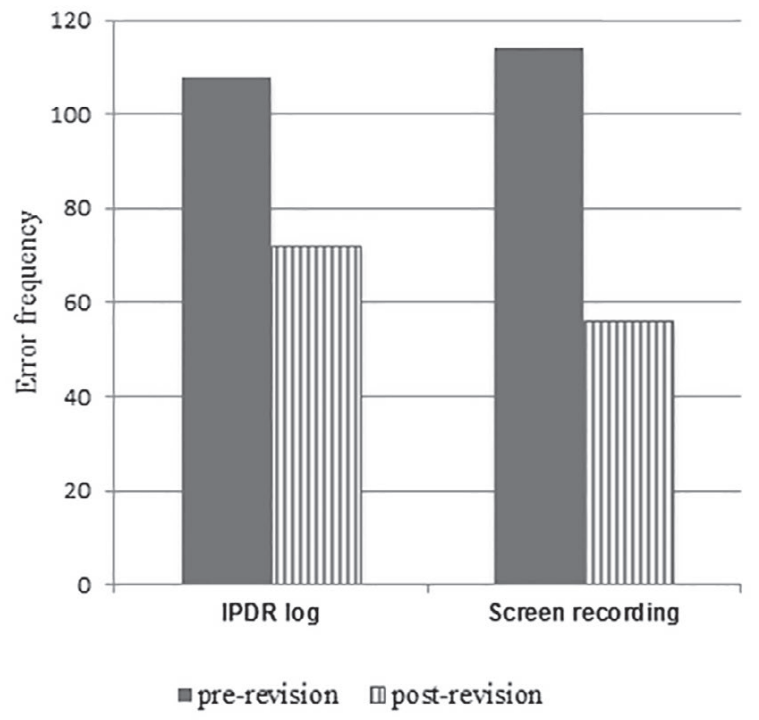

Figure 2. Overall error mitigation pre- and post-revision by process protocol. 
However, our second hypothesis was only partially confirmed. If we examine the effect of the process protocol mode used during revision on the errors for each error category, our study demonstrated improved mitigation in only four of the six error categories. We see that screen recording is more effective in the mitigation of punctuation, spelling, syntax, and mistranslation errors, while it is nearly or just as effective as IPDR in the mitigation of errors in lexis and style (see figure 3 ).

To put these results in perspective (see table 4), one of the error categories did not have very many instances; the spelling error category only had 4 instances over the entire set of texts and only one of those instances (mitigated) was in the SR condition. Lexical, stylistic, and mistranslation errors were both present in high frequencies and reasonably balanced between the two conditions. This was purely fortuitous, because we could not control for the errors made in the TTs. The punctuation and syntactic categories were not balanced between the two conditions, although in both conditions SR mitigated a larger absolute number of errors. Thus, we hesitate to draw any strong conclusions about punctuation, spelling and syntax. The error counts for lexis, style, and mistranslation are robust and balanced. Of these, only mistranslation shows a large effect for the SR process protocol. Here, IPDR only mitigated 12 of 53 errors (23\%), while SR mitigated 24 of 47 errors (51)\%. This was by far the most dramatic result from our study and matches with a similar result for mistranslation in Angelone's study, where mistranslation also seemed to produce the most dramatic result.

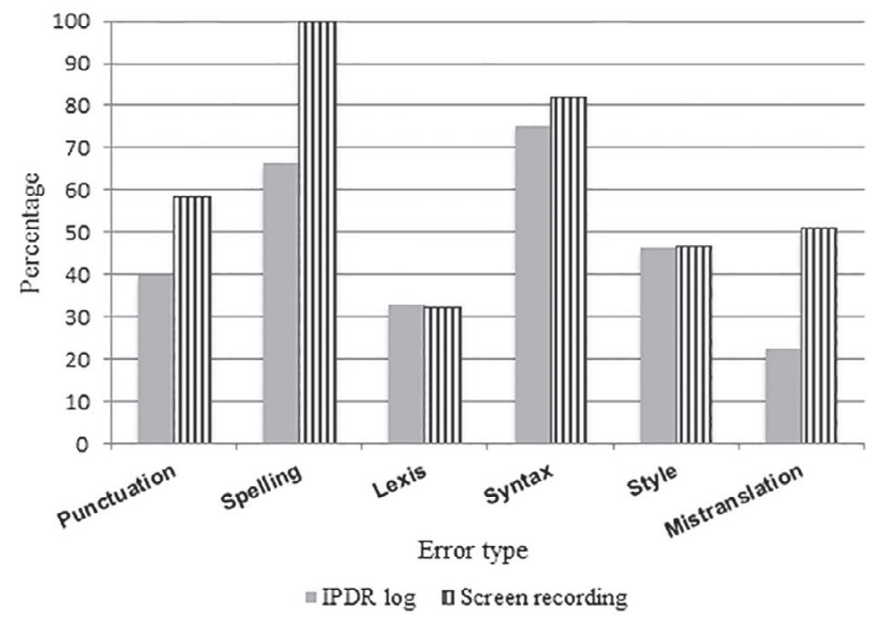

Figure 3. Error mitigation by error type and process protocol. 


\begin{tabular}{|c|r|c|c|c|c|c|r|r|r|r|r|c|}
\hline ERR & \multicolumn{2}{|c|}{ PU } & \multicolumn{2}{c|}{ SP } & \multicolumn{2}{c|}{ LEX } & \multicolumn{2}{c|}{ SYN } & \multicolumn{2}{c|}{ STY } & \multicolumn{2}{c|}{ MIS } \\
\hline & TT & ETT & TT & ETT & TT & ETT & TT & ETT & TT & ETT & TT & ETT \\
\hline IPDR & 5 & 3 & 3 & 1 & 27 & 18 & 4 & 1 & 15 & 8 & 53 & 41 \\
\hline SR & 12 & 5 & 1 & 0 & 25 & 17 & 11 & 2 & 15 & 8 & 47 & 23 \\
\hline TOT & 17 & 8 & 4 & 1 & 52 & 35 & 15 & 3 & 30 & 16 & 100 & 64 \\
\hline
\end{tabular}

Table 4. Error counts by error category.

\section{Discussion}

The results of our experiment indicated that, as in Angelone's 2011 study, screen recording is significantly more efficacious overall than IPDR logs in mitigating translation errors. We did not entirely duplicate Angelone's results for the individual error categories, and this may very well have to do with the nature of the sample, sample size, and lack of control over the total number of errors and errors within each process protocol set. A more robust data set may produce different results. The failure to duplicate the error category results may also have to do with the possible cognitive differences between other-revision and self-revision. Nevertheless, we did find some congruences: $\mathrm{SR}$ is still efficacious in mitigating very small, granular errors (punctuation) and certain more global ones (mistranslation).

How do we explain SR's apparent overall advantage in both self-revision, as in Angelone's study, and in other-revision? In his 2011 study, Angelone argued that the "guided" eye movements that occur when a self-editor views a screen recording make the locations of "areas of difficulty" originally encountered in the text more salient during the revision phase. Any problem indicators (pausing, revision activity, look-up activity) are brought to the reviser's attention and can be re-considered during the revision phase. Angelone remarked that the students' "visual attention is inherently drawn to problems as they unfold in real-time." We agree that, when compared to IPDRs (and TAPs, as in the original study), SRs simply provide more detail to use in bringing the reviser's attention to areas of difficulty. Not only that, they provide that detail in a temporal sequence and in their full "event context." We will return to the notions of event and event context again.

In self-revision, one obvious additional explanation for SR's advantage has to do with the nature of episodic memory. Episodic memory is a type of long-term memory that involves the recollection of specific events, situations, and experiences; it is the capacity to consciously remember personally experienced events and situations. Recall of past experience can be enhanced when 
information available during encoding is also present at retrieval. Tulving \& Thomson (1973: 359) called this the "encoding specificity principle."

One could make the case that the use of any sufficiently detailed process protocol mode makes such information available. TAPs, IPDR logs, and SRs all have the possibility of providing important cues that trigger recall and enhance retrieval from episodic memory. Screen recordings, arguably, simply provide a much richer set of detailed cuing information than either TAPs or IPDR logs. Indeed, in Angelone's original results, where screen recording was more effective in mitigating smaller granular errors than IPDR, he remarked that "it almost seems as if students preferred documenting "bigger issues" when using IPDRs. There were fewer entries regarding punctuation, spelling, and lexis overall. Participants in his studies used their IPDR logs primarily to document syntactic and stylistic issues. That pattern seems to have been repeated in our study.

Indeed, the issue that arises here is one of filtering. IPDR logs (and, indeed, even TAPs) are "active" logging protocols; that is to say they require the translator to, as Angelone says, "break away from the task at hand." This breaking away probably not only pulls the participant's attention away from the ongoing activity of the translation, but also engages a selection mechanism. The participant has to decide which events to document. Smaller, more frequent events will not be selected for logging in favor of more striking or unusual problem events. Screen recordings, on the other hand, are "passive" logging protocols; by their very nature they capture all activity without having to break away from the task or engage a selection mechanism. One might argue that passive logging produces too much detail, e.g., produces as much cuing noise as it does relevant cuing data. With a more active logging protocol the participant benefits, one could argue, from a mechanism that "selects" what is important to pay attention to, that is, directs the focus of attention. We argue that screen recording, although it is a passive logging procedure, does, in fact produce little noise and is quite effective in providing the participant (other-reviser, self-reviser) with a rich set of relevant cues. It does this by effectively cuing the structured recognition of events.

The richness of the cues generated by screen recordings raises two questions. First, in what important way is a screen recording richer than a TAP or an IPDR log? We know that screen recordings contain more visual information than either TAPs or IPDR and they are not subject to the filtering effects of the other two protocols. They are, in some ways, more natural, more like re-living the event. Maybe re-experiencing the event helps participants retrieve important information about what problems they were solving, what 
difficulties they were having in generating solutions, and, indeed what they were attempting to accomplish in their translations. The second issue proceeds from the first. If an SR is more like "re-living the event," how can we explain its efficacy in other-revision? We can't find an explanation for the efficacy of screen recording in the greater richness and naturalness of cuing information in the SR log, because we are not cuing the episodic memory and improving the recall of the original translator.

Event segmentation theory (EST) can help provide an answer to that question (Zacks et al. 2007: 273). According to this theory, human beings naturally and spontaneously segment the ongoing continuous activities that occur around them. These segments or events are demarcated along "event boundaries" constructed from "breaks" (perceptions of changes in motion, frequency, or the composition of objects and their backgrounds). As part of normal perceptual processing, the brain chunks reality into meaningful segments; the chunking plays an essential role in attention, control, and episodic memory encoding (Zacks \& Sargent 2010: 8).

Event segmentation is always active in working memory, creating representations of "what is happening now" (Zacks 2010). The basic assumption of EST is that these representations of events exist in working memory because they improve our perception of what is happening and our ability to predict what comes next. One can think of an event representation as a transient model that represents the activity currently being perceived. The model is stable and remains in effect, accommodating minor fluctuations in the perceptual input. However if unexpected or unpredicted change occurs, then so-called "prediction error" increases. The locus where change occurs and the predictive ability of the event model decreases is the so-called event boundary (Zacks 2010). A new event model arises to account for the new stream of experience.

Event segmentation affects how information about experience is encoded into episodic long-term memory. According to Newston (1976), event boundaries are anchors in long-term memory and any experiential information encoded at event boundaries is remembered better. In a variety of empirical studies, event boundaries have been shown to be associated with increased recall of events (Newston \& Engquist 1976; Schwan \& Garsoffky 2004; Ginsburg \& Smith 1993). So episodic memory is indeed not just about remembering everything that we have experienced, it is a memory of events whose structure is related to the event models and event boundaries used to encode it. 
The notion of event models as a mechanism may explain why screen recording is efficacious in both self- and other-revision. In self-revision, the screen recording helps the user "recreate" the events of the past and retrieve from memory the details of the event boundaries (translation activity pauses, periods of text production activity, reference-related internet lookups, text revision activity, and so on). Unlike TAPs and IPDR logs, it allows unprecedented access to the discrete "event structure" of the activity that occurs in an application such as MS Word and also provides that same information about searching activity on the Internet, and activity involving translation memories and terminology managers. These applications are used concurrently with the main translation activity in the word processor and provide important contextual information about the cognitive processing of the translator. Not only does screen recording provide us with an "event stream" within each application, it allows us to see how the discrete application-oriented activities intersect with one another in real-time; at each intersection, arguably, there is a context change, an "event boundary" that can be perceived by a viewer and become a focus of attention in the attempt to reconstruct the translation problem-solving activity of the original translator. Screen recording provides, as we have argued, very granular detail; every action is recorded. It not only allows a reconstruction of the stream of events and makes explicit both intra- and inter-application event boundaries (e.g., the transition between comprehension, initial text production, and revision), but also provides the original temporal data (e.g., the specific sequence of activities and real-time preservation of durations and pauses). Screen recording provides an almost "cinematic" narrative flow to the activity that occurs within and between applications.

There has been some empirical work on the role of "logging methods" in improving recall. Sellen et al. (2007: 82) argued that logging methods that provided rich detail (they used a wearable SenseCam that passively stored images) enhance "the recollection of specific details of recent past events (remembering what one perceived or felt at the time of an event)." Based on Cangiano's notion of "reinstating context", we claim that the same rich detail and re-enactment of past events provided by detailed logging or process protocol methods also produces a benefit when such logs are viewed by others:

From the theoretical perspective of EST [...] we can think of reinstating context really as an act of "re-perceiving." In other words, perceiving again the same structural and temporal relations used to guide attention and memory during the original performance of the activity. (Cangiano 2011: 22). 
In other-revision, the screen recording allows the other-reviser to perceive the same events that the original translator perceived. In their study of everyday activities in a law office, Cangiano \& Hollan (2009: 946) argue that "if we are to move towards understanding and supporting real activities, what is needed is access to episodic views of activity within and across applications and resources." If we provide that access to another, instead of the person who lived the activity, what occurs? We suggest that by reinstating a past context (e.g., the entire event stream of another's previous activity) we allow the other (translator, reviser, etc.) to use that event stream to create a context for interpreting the results they are revising. As Zacks \& Sargent (2010) remark, "[e]vent models combine current perceptual information with information acquired very recently in the present context, and with patterns of information learned over a lifetime of experience" (Zacks \& Sargent 2010: 4). These long-term patterns of information are the accretions of "commonly activated event models," what Zacks \& Sargent (2010: 14) call "event schemata" in long-term memory.

Let us assume that the activity performed by people who share a task domain will, at least in its gross aspects, resemble the activities of others who have performed this same activity in similar contexts. The apparent advantage of screen recording in other-translation is still based on episodic memory, but what we are recalling or remembering are our own similar or analogous activities, filtered through our own event schemata, triggered by the observation of the recorded event stream produced by a colleague who practices in the same task domain as we do.

This advantage would most likely disappear if the screen recordings were shown to individuals, for instance in this case, who were not translators. Their past activities do not include translation; they therefore have not accreted event schemata about translation. They cannot use the events they see in a screen recording to trigger recognition of the nature and importance of the events. Mind you, such non-practitioners may still parse the event stream and recognize events (e.g., someone is doing word processing; someone is doing a Google search) because they do have schemata for these more general events. But their observation of a screen recording will not trigger any information about the translation-relevance of the events they perceive. If this is the case, we should see a strong expertise effect in the efficacy of screen recordings in both self- and other-revising. 


\section{Conclusion}

Clearly, the research that Angelone began, and that we have pursued, is in its infancy, and there are many open questions. For instance, keystroke logs and eye-tracking methods are finely detailed and also passive recording systems. They have some of the same characteristics as SRs. However, will they, can they, allow editors to reinstate context and interpret the event structure of a past translation activity as effectively as screen recording? Or is screen recording's exact and natural presentation of the past the key?

Also, our results in specific error categories showed some differences in the efficacy of SR when used for self-revision and other-revision. Future studies might use a larger, more balanced data set to determine whether there are cognitive differences between self- and other-revision (for instance, the specificity that derives from recalling one's own memories) that could explain this variation in results. It might also be useful to compare self- and other-revision directly within the same experiment, manipulating experimental factors to give a better idea about where these two forms of editing converge and where they diverge. Is screen recording in self-revision more efficacious than in other-revision, and is the result time sensitive? If we conduct a self-revision session immediately post-translation, a week after, a month after, will we then see a decline in efficacy, reflecting an increasing dependence on the event schemata for recognition rather than recall and remembering?

Finally, an important future line of investigation would be to explore the interaction of expertise and using process protocols for support during selfand other-revision. For instance, does the efficacy of screen recording (or indeed of any process-protocol) remain "stable" during the development of expertise, or does it increase or decline? In other words, are such protocols of greatest "effect" for self-revision earlier in one's professional career, with benefits tapering off as expertise increases? If there is greater benefit in early career, then this argues primarily for the pedagogical value of using process protocols. In novices and early career translators such as our participants, it may be that the efficacy of screen recording in self-revision is partially correlated with the fact that the absolute number of errors in all categories after the initial translation is completed is relatively large. There are many more errors (of all six categories) to be mitigated. Fewer errors are revised concurrently, either before or soon after the translated segment is exited, or before the initial translation session ends (for example, when a translator returns to an earlier segment after translating subsequent segments). Awareness of error during the task is less developed because that aspect of translation metacognition is less developed. If experts, as one would expect, commit fewer errors in the 
first place, and those errors they do make are corrected before the translation session ends, then the efficacy of screen recording in self-revision will be less dramatic in absolute terms. We will see a drop-off in the utility of the protocol as a method to assist self-revision.

On the other hand, the efficacy of screen recording for other-revision should show a dramatic expertise effect since it depends, we would argue, on the strength of event schemata for translation. We contend that the formation and application of such schemata are a part of task awareness, and an important aspect of metacognition. Thus, the more expert the translator, the more he or she would "recognize" the import of the screen activity being viewed. The more developed the translation expertise, the more the reviser could extract from the recording. However, it would remain an open question, perhaps one for experimental investigation, as to whether an expert using a screen protocol to other-revise would significantly out-perform another expert simply reading and other-revising the translation without support. In other words, is the expertise itself the primary key to success in other-revising?

Angelone's original study was undertaken in the context of translation pedagogy. He wanted to explore ways to assist students in understanding "how one translates" (Angelone 2013: 1). By using process protocols as a support during self-revision, particularly screen recordings, he argued one could effectively engage and direct students' self-reflection on their own translation processes. The process protocols become a device to spur the development of metacognitive awareness of the translation task. Our study indicates that screen recording is equally beneficial in helping students understand the processes of others. So, from a pedagogical perspective the technique has merit for both self- and other-revision. It is not clear if the findings of these studies have practical application in the workplace, e.g., as part of editing practice. The effort and time involved in obtaining recordings and then using them during editing would probably not be outweighed by the expected benefits from error reduction.

\section{References}

ANGELONE, Erik. (2013) "The impact of process protocol self-analysis on errors in the translation product." Translation and Interpreting Studies 8:2, pp. 253-271.

Cangiano, Gaston. (2011) Studying Episodic Access to Personal Digital Activity: Activity Trails Prototype. PhD dissertation, University of California, San Diego.

CANGIANO, Gaston \& James Hollan. (2009) "Capturing and restoring the context of everyday work: A case study at a law office." Human Computer Interaction 10:5619, pp. 945-954. 
GILE, Daniel. (2004) "Integrated problem and decision reporting as a translator training tool." JoSTrans 2. Electronic version available at: <http://www.jostrans.org/issue02/art_gile.php> on 20 October 2012.

GINSBURG, Gerald \& David Smith. (1993) "Exploration of the detectable structure of social episodes: the parsing of interaction specimens." Ecological Psychology 5:3, pp. 195-233.

Kiraly, Donald C. (1995) Pathways to Translation: Pedagogy and Process. Kent, $\mathrm{OH}$ : Kent State University Press.

KüNZLI, Alexander. (2007) "A study of the performance of ten professional translators revising a legal text." In: Gambier, Yves; Miriam Shlesinger \& Radegundis Stolze (eds.) 2007. Doubts and Directions in Translation Studies. Amsterdam: John Benjamins, pp. 115-126.

MASSEY, Gary; Maureen Ehrensberger-Dow \& Andrea Hunziker Heeb. (2013) "Defining phases of the translation process: Revision as a case in point." Conference paper presented at GAL 2 Sektionentagung, "Übersetzungs- und Dolmetschwissenschaft: Makrodefinitionen und Mikrodefinitionen." RWTH Aachen, Germany, 19-20 September 2013.

NEWSTON, Darren. (1976) "Foundations of attribution: The perception of ongoing behavior." In: Harvey, John H.; William J. Ickes \& Robert F. Kidd (eds.) 1976. New Directions in Attribution Research. Hillsdale, NJ: Lawrence Erlbaum Associates, pp. 223-248.

NeWston, Darren \& Gretchen Engquist. (1976) "The perceptual organization of ongoing behavior." Journal of Experimental Social Psychology 12:5, pp. 436-450.

SCHWAN, Stephan \& Bärbel Garsoffky. (2004) "The cognitive representation of filmic event summaries." Applied Cognitive Psychology 18:1, pp. 37-56.

SEllen, Abigail; Andrew Fogg; Mike Aitken; Steve Hodges; Carsten Rother \& Ken Wood. (2007) "Do life-logging technologies support memory for the past? An experimental study using SenseCam.” In: Begole, B.; S. Payne; E. Churchill; R. St. Amant; D. Gilmore \& M. Rosson (eds.) 2007. Proceedings of the SIGCHI Conference on Human Factors in Computing Systems. New York: ACM Press, pp. 81-90.

SHREVE, Gregory. (2006) "The deliberate practice: Translation and expertise." Journal of Translation Studies 9:1, pp. 27-42.

Tulving, Endel \& Donald Thomson. (1973) "Encoding specificity and retrieval processes in episodic memory." Psychological Review 80:5, pp. 352-373.

ZACKS, Jeffrey. (2010) "How we organize our experience into events." Psychological Science Agenda 24:4. Electronic version available at: <http://www.apa.org/ science/about/psa/2010/04/sci-brief.aspx> on 22 October 2012. 
ZACKS, Jeffrey \& Jesse Sargent. (2010) "Event perception: A theory and its application to clinical neuroscience." In: Ross, Brian H (ed.) 2010. Psychology of Learning and Motivation, Vol. 53. San Diego, CA: Academic Press, pp. 253-299. ZACKS, Jeffrey; Nicole Speer; Khena Swallow; Todd Braver \& Jeremy Reynolds. (2007) "Event perception: A mind/brain perspective." Psychological Bulletin 133:2, pp. 273-293.

\section{BIONOTES / NOTAS BIOGRÁFICAS}

Gregory M. Shreve is Emeritus Professor of Translation Studies at Kent State University and Adjunct Professor of Translation Studies at New York University. He is co-editor and co-author of several books on translation including Translation as Text, Cognitive Processes in Translation and Interpreting and Translation and Cognition. His research specialties include translation theory and cognitive processes in translation.

Gregory M. Shreve es Catedrático Emérito de Estudios de Traducción en Kent State University (Ohio) y Profesor Adjunto de Estudios de Traducción en la Universidad de Nueva York. Es co-editor y co-autor de varios libros sobre traducción, entre ellos Translation as Text, Cognitive Processes in Translation and Interpreting y Translation and Cognition. Sus areas de investigación incluyen teoría de la traducción y los procesos cognitivos relacionados con la traducción.

Erik Angelone is Associate Professor of Translation Studies at Kent State University. He received his Ph.D. in Translation Studies from the University of Heidelberg. His current research interests include process-oriented translator training, cognitive processes in translation, and intercultural communicative competence. He recently co-edited a volume titled Translation and Cognition (John Benjamins 2010) with Dr. Gregory Shreve.

Erik Angelone se doctoró en Estudios de Traducción por la Universidad de Heidelberg y actualmente es Profesor Asociado de Estudios de Traducción en Kent State University (Ohio). Sus areas de investigación incluyen pedagogía de la traducción desde el punto de vista del proceso, los procesos cognitivos relacionados con la traducción y la competencia comunicativa intercultural. Recientemente ha sido co-editor del volumen titulado Translation and Cognition (John Benjamins 2010) con Dr. Gregory Shreve. 
Isabel Lacruz is Assistant Profesor of Translation Studies at Kent State University. She received her Ph.D. in Experimental Psychology from Kent State University. Her current research interests focus on the cognitive processes involved in translation and post-editing.

Isabel Lacruz es doctora en Psicología Experimental por la Kent State University (Ohio) y actualmente es Profesora Asistente de Estudios de Traducción en esa universidad. Su investigación se centra en los procesos cognitivos relacionados con la traducción y post-edición. 